\title{
HABITAT COMPLEXITY INFLUENCES CASCADING EFFECTS OF MULTIPLE PREDATORS
}

\author{
Jonathan H. Grabowski, ${ }^{1,3}$ A. Randall Hughes, ${ }^{2}$ and David L. Kimbro ${ }^{2}$ \\ ${ }^{1}$ University of North Carolina at Chapel Hill, Institute of Marine Sciences, Morehead City, North Carolina 28557 USA \\ ${ }^{2}$ University of California at Davis, Bodega Bay, California 94923 USA
}

\begin{abstract}
Although multiple predator effects and trophic cascades have both been demonstrated in a wide variety of ecosystems, ecologists have yet to incorporate these studies into an experimental framework that also manipulates a common and likely important factor, spatial heterogeneity. We manipulated habitat complexity, the presence of two top predators (toadfish and blue crabs), and one intermediate predator (mud crabs) to determine whether habitat complexity influences the strength of multiple predator interactions across multiple trophic levels in experimental oyster reef communities. In the absence of toadfish, blue crabs caused significant mud crab mortality. Despite also directly consuming mud crabs, toadfish indirectly benefited this intermediate predator by decreasing blue crab consumption of mud crabs. Toadfish suppression of mud crab foraging activity, and thus decreased mud crab encounters with blue crabs, is likely responsible for this counterintuitive result. Contrary to previous investigations which suggest that more complex habitats reduce interference interactions among predators, reef complexity strengthened emergent multiple predator effects (MPEs) on mud crabs. The degree to which these MPEs cascaded down to benefit juvenile oysters (basal prey) depended on both habitat complexity and nonconsumptive effects derived from predator-predator interactions. Habitat complexity reduced the foraging efficiency of each crab species individually but released crab interference interactions when together, so that the two crabs collectively consumed more oysters on complex reefs. Regardless of reef complexity, toadfish consistently decreased consumption of oysters by both $\mathrm{crab}$ species individually and when together. Therefore, interactions between predator identity and habitat complexity structure trophic cascades on oyster reefs. Furthermore, these cascading effects of multiple predators were largely mediated by nonconsumptive effects in this system.

Key words: blue crabs; consumptive effects; density-mediated indirect interactions (DMIIs); habitat complexity; mud crabs; multiple-predator interactions; nonconsumptive effects; oysters; predator avoidance behavior; toadfish; trait-mediated indirect interactions (TMIIs); trophic cascades.
\end{abstract}

\section{INTRODUCTION}

How predators help organize ecological communities has been one of the most intensively studied subjects in ecology (Abrams 1982, Sih et al. 1985, 1998, Lima and Dill 1990, Bruno and O'Conner 2005). In addition to increasing prey diversity by preferentially consuming competitively dominant species (Paine 1966), predators can have effects that cascade to lower trophic levels when they consume (density mediated) or alter the foraging behavior (trait mediated) of consumers at intermediate trophic levels (Carpenter et al. 1985, Strong 1992, Schmitz et al. 2000, 2004, Werner and Peacor 2003). Historically, predation research tested the effects of adding or removing a single predator species, yet there is now considerable evidence that interactions among multiple predators can have important and often

Manuscript received 27 June 2007; revised 19 March 2008; accepted 19 March 2008. Corresponding Editor: S. P. Lawler.

${ }^{3}$ Present address: Gulf of Maine Research Institute, 350 Commercial Street, Portland, Maine 04101 USA.

E-mail: jgrabowski@gmri.org counterintuitive consequences for their immediate prey (Soluk and Collins 1988, Wissinger and McGrady 1993, Morin 1995, Crowder et al. 1997, Sih et al. 1998, Eklov and VanKooten 2001) as well as lower trophic levels (Duffy 2002, Byrnes et al. 2006). Because most natural communities contain numerous predator species, predicting the distribution and density of prey species likely requires an understanding of interactions among predators as well as their consumptive and nonconsumptive impacts on their prey.

Habitat complexity can also strongly influence the strength of predation (and thus trophic cascades) in natural communities (Huffaker 1958, Murdoch and Oaten 1975, Crowder and Cooper 1982, Trussell et al. 2006). For instance, predators may consume less prey when the structural elements associated with complex habitats affect the ability of predators to detect prey, or when refuge habitats reduce the predator's ability to catch intermediate consumers (Holbrook and Schmitt 1988, Sih et al. 1992), potentially dampening trophic cascades. This reduced predation pressure within complex habitats may partly explain why complex habitats 
are often characterized by dense and speciose assemblages (Heck and Thoman 1981, Diehl 1988, 1992, Bell et al. 1991). In addition to influencing predator-prey interactions, habitat context can also alter interactions among predators. For example, habitat complexity generally decreases encounter rates among predators, thereby reducing the strength of interference interactions and intraguild predation (Swisher et al. 1998, Finke and Denno 2002, Grabowski and Powers 2004, Siddon and Witman 2004, Griffen and Byers 2006, Hughes and Grabowski 2006). Although each of these studies compared multiple predator effects in different habitat types of varying complexity (rather than by manipulating habitat complexity within a particular system), collectively they suggest that habitat complexity may increase the strength of predator effects by reducing interference interactions and intraguild predation. Because of these contrasting effects of habitat complexity on predator-prey vs. predator-predator interactions, it remains unclear how habitat complexity ultimately impacts trophic cascades involving multiple predators.

While recent studies of trophic cascades have focused on the independent consequences of multiple predators and habitat complexity, ecologists have yet to fully integrate how the interaction between habitat complexity and multiple predators influences the relative strength of trophic cascades. Almost all systems are characterized by multiple predators and variation in habitat complexity. Therefore, investigating how these factors influence food web interactions is a logical step to improve our understanding of how trophic cascades, a central focus in community ecology, operate in natural systems. Greater understanding of these interactions is especially necessary given that human impacts historically have been greatest on higher trophic levels and that extensive degradation of more complex habitats such as rain forests, coral reefs, oyster reefs, and seagrass beds has occurred worldwide (Rothschild et al. 1994, Jackson et al. 2001, Coleman and Williams 2002, Duffy 2002).

Although trophic cascades have been demonstrated in many ecosystems, marine benthic communities are thought to generate the strongest trophic cascades in nature (Shurin et al. 2002). Thus they offer a model system in which to test the interactive effects of habitat complexity and multiple predators on trophic cascades. In this study, we examined how multiple predators and habitat complexity interact to affect trophic cascades in oyster reef communities. We chose oyster reef habitat because it consists of aggregate oyster clusters that provide vertical relief and consequently increase habitat complexity (Lenihan 1999, Lenihan et al. 2001). In addition, habitat complexity naturally varies on oyster reefs as a function of the degree to which oysters successfully recruit to, grow, and persist on oyster reefs (see Plate 1). Oyster reef habitat also supports extremely dense assemblages of resident intermediate predators and basal prey (polychaetes, mollusks, decapods, and other invertebrates), and is utilized by multiple top predators such as juvenile and adult fish, large crustaceans, and whelks (Wells 1961, Ulanowicz and Tuttle 1992, Coen et al. 1999, Peterson et al. 2003, Grabowski et al. 2005). The oyster toadfish indirectly benefits oysters by inducing mud crabs (intermediate consumer) to occupy a deeper portion of the reef matrix and move less frequently (Grabowski 2004, Grabowski and Kimbro 2005). Even though habitat complexity inhibits toadfish consumption of mud crabs, toadfish still indirectly benefit oysters because the strength of these nonconsumptive effects is much larger than that of the consumptive effects. However, adult blue crabs are generalists that also frequent these oyster reefs and may weaken this trophic cascade by competitively interfering with toadfish for mud crabs and/or by foraging on oysters rather than on mud crabs. Thus, we investigated whether the cascading effects of these two top predators are consistent within oyster reefs of varying complexity, while also determining if interactions between these two top predators modify trophic cascades.

To test how habitat complexity and interactions among top predators influence the strength of trophic cascades, we conducted a mesocosm experiment that manipulated oyster reef habitat complexity, the presence of two top predators (oyster toadfish, blue crab), and an intermediate predator (mud crabs) to quantify how these factors mediate mud crab and juvenile oyster survivorship (see Fig. 1 for hypothesized food web). Based on previous work in this system (Grabowski 2004, Grabowski and Kimbro 2005, Hughes and Grabowski 2006), we predicted the following: (1) In simple environments, blue crabs will benefit oysters (the basal prey) by suppressing intermediate prey (mud crabs); reef complexity will weaken suppression of mud crabs by blue crabs, thus reducing the trophic cascade from blue crabs to oysters. (2) Toadfish will strengthen trophic cascades by suppressing mud crab foraging, thus reducing predation on oysters, while also reducing predation by blue crabs on mud crabs (3) Reef complexity may reduce interference between blue crabs and toadfish but the trophic cascade will remain strong because mud crabs avoid toadfish even in complex habitats.

\section{Methods}

The experiments were conducted at the University of North Carolina, Institute of Marine Sciences in Morehead City, North Carolina, USA, between July and November of 1999. Experiments were conducted in sixteen cylindrical, plastic pools $(1.7 \mathrm{~m}$ wide $\times 0.3 \mathrm{~m}$ tall). Pools were enclosed with 6-mm mesh plastic fence extending to $20 \mathrm{~cm}$ above the water surface to prevent fish and crabs from escaping, and were covered with 10mm mesh netting to exclude birds and other terrestrial predators. During the experiment, these pools were placed within a concrete tank $(6 \times 9 \times 1.2 \mathrm{~m})$ filled to 1 $m$ with unfiltered seawater from Bogue Sound, North Carolina. The tank received a continuous (0.27-0.29 


\section{Simple reef}

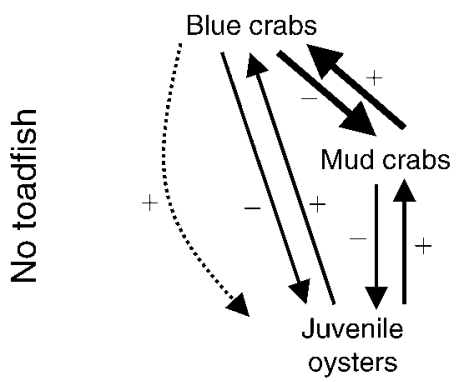

Complex reef

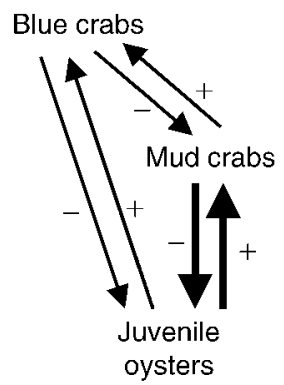

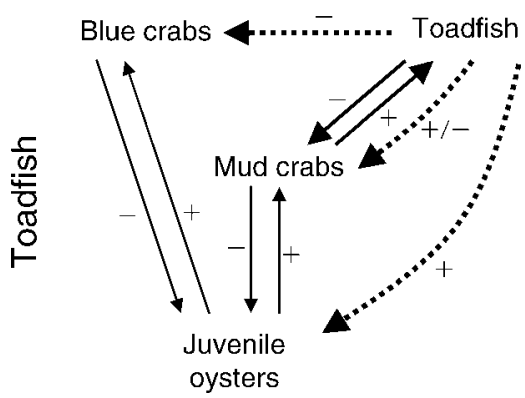

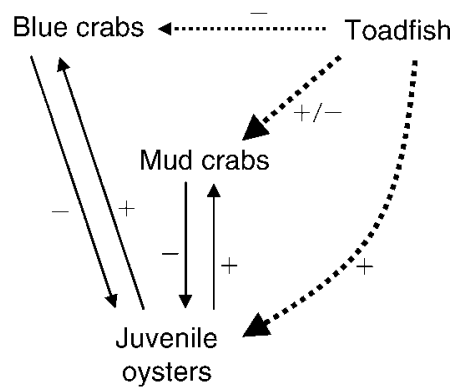

FIG. 1. Hypothesized food web interactions on oyster reefs. Solid lines indicate direct trophic interactions. Dashed lines indicate either a net indirect effect of top predators on mud crabs or juvenile oysters propagated by either a density-mediated (e.g., blue crabs increase oyster survival by consuming mud crabs in the upper left panel) or trait-mediated (e.g., toadfish induce mud crabs to move deeper within the reef and suppress their foraging behavior) interaction. Arrows indicate the direction and strength (arrow thickness) of the interaction among species pairs, and the sign indicates the net outcome. The arrow between toadfish and mud crabs in the lower two panels has both a + and - because toadfish indirectly benefit mud crabs by interfering with blue crab consumption of mud crabs but also negatively affect them by reducing their consumption of oysters.

$\mathrm{L} / \mathrm{s}$ ) supply of seawater from the perimeter along the top to aerate the water in the tank. Water in the tank then drained into a standpipe located in a corner.

Using a $2 \times 2 \times 2 \times 2$ factorial design, we manipulated habitat complexity (high or low), toadfish (present or absent), blue crabs (present or absent), and mud crabs (present or absent). Our response variables included mud crab survivorship (first three factors only) and juvenile oyster survivorship. Because the settling tank prohibited conducting more than one replicate per experimental run, we treated experimental run as a blocking factor and conducted four separate experimental runs during the summer and fall months of 1999. An additive design was utilized in this experiment in order to examine the effects of habitat complexity on predator-predator and predator-prey interactions on oyster reefs of differing complexity. Although substitutable designs permit partitioning of identity and density effects of multiple predators, we chose an additive design in order to be able to examine other factors (i.e., cascading effects of predators across three trophic levels and habitat complexity) simultaneously. Therefore, we have been careful to avoid inferring that emergent multiple predator effects definitely exist in this system.

To manipulate the level of habitat complexity, we constructed experimental oyster reefs in each pool by depositing either 20 gallons $(75.71 \mathrm{~L})$ of unaggregated dead individual oyster shells (low complexity: $0-5 \mathrm{~cm}$ of vertical relief) or 5 gallons $(18.91 \mathrm{~L})$ of unaggregated oyster shell covered with 15 gallons $(56.81 \mathrm{~L})$ of dead oyster clusters (high complexity: 10-30 cm vertical relief). Within the experimental reefs, juvenile oysters $(12.3 \pm 0.7 \mathrm{~mm}$ shell height, mean $\pm \mathrm{SE})$ were attached to dead shells (10 per shell) and four shells (i.e., 40 juvenile oysters) were added to each enclosure; methods are described in Grabowski (2004). Forty adult mud crabs $(26.6 \pm 1.0 \mathrm{~mm}$ carapace width $[\mathrm{CW}])$, one blue crab $(138.3 \pm 7.5 \mathrm{~mm} \mathrm{CW})$, and one toadfish $(180.0 \pm$ $4.8 \mathrm{~mm}$ standard length [SL]) were added to four low and four high complexity reefs to achieve a factorial design with every possible combination of predators in both habitats during each experimental run. Predator densities and size ranges are consistent with the demography of these species in the wild (McDermott and Flower 1952, Wilson et al. 1982, Meyer et al. 1996, Grabowski et al. 2005; J. H. Grabowski, unpublished data). After each six-day experimental trial was completed, each pool's shell material was sieved to quantify the number of living, dead, and missing mud crabs and juvenile oysters. We then released surviving animals from the previous experimental run, randomly reassigned treatments, and reconstructed pool environments with recently collected organisms. 
Mud crabs and toadfish were collected on oyster reefs in Back Sound, Carteret County, North Carolina. Before each experiment, these organisms were stored for $\sim 3-4$ days in separate upwellers and fed crushed ribbed mussels (Geukensia demissa). Crushed ribbed mussels $(96.7 \pm 0.4 \mathrm{~g})$ were deposited in each pool at the beginning of each experimental run to provide an alternative food source and to avoid starvation of predators. Use of unfiltered water resulted in several additional small prey organisms (largely polychaetes and small crustaceans) entering the individual enclosures (Martin et al. 1989; J. H. Grabowski, personal observation).

\section{Statistical analyses}

Cochran's test for homogeneity of variance was conducted on all main effects in each analysis (Underwood 1981). Oyster mortality data were arcsine transformed to conform to the assumption of homogenous variances (geometric means are reported in the results). We analyzed the effects of habitat complexity, toadfish presence, blue crab presence, and experimental run (block) on mud crab mortality using a four-way ANOVA. We also conducted a five-way blocked ANOVA on juvenile oyster mortality with habitat complexity, toadfish presence, blue crab presence, mud crab presence, and experimental run (block) as fixed factors. Block effects were not significant $(P>0.25)$ and consequently were removed from the analyses and data were reanalyzed (Underwood 1981). We conducted Student-Newman-Keuls (SNK) post hoc tests on all significant interaction terms and main effects because we conducted a balanced design with a priori predictions and fixed factors (Day and Quinn 1989).

Three treatments in this experiment exhibited prey depletion: mud crabs in the absence of toadfish $(99.1 \%$ oyster mortality), blue crabs alone on low-complexity reefs $(91.9 \%$ oyster mortality), and both crab species in high-complexity reefs $(91.3 \%$ oyster mortality). For all other treatments, prey depletion was less than $\sim 70 \%$. For mud crabs in the absence of toadfish, we utilized data from a complementary 24-hour assay to quantify per capita oyster mortality. In the 24-hour assay, five replicates of each complexity level were constructed within separate pools and organisms were added using methods identical to the six-day experimental runs (see Grabowski 2004). Consequently, oyster mortality levels for all other treatments were divided by 6 in order to standardize (to number per day) all oyster mortality results for statistical analysis.

Following the ANOVA on mud crab mortality, we compared the mortality rate of mud crabs from the toadfish + blue crab treatment to a predicted value using a Student's $t$ test to detect whether nonlinear multiplepredator effects occurred at each level of habitat complexity (Schmitz and Sokol-Hessner 2002, Siddon and Witman 2004). Predicted values were calculated using a multiplicative risk model to determine the expected mud crab survivorship when both toadfish and blue crabs are present:

$S_{(\mathrm{MC}) \mathrm{T}+\mathrm{BC}^{\mathrm{e}}}=1-M_{(\mathrm{MC}) \mathrm{T}}-M_{(\mathrm{MC}) \mathrm{BC}}+M_{(\mathrm{MC}) \mathrm{T}} \times M_{(\mathrm{MC}) \mathrm{BC}}$

where $M_{(\mathrm{MC}) \mathrm{T}}$ and $M_{(\mathrm{MC}) \mathrm{BC}}$ are the mud crab mortality rates induced by toadfish and blue crabs, respectively, when each top predator is alone. These survivorship data were log-transformed prior to analyses (see Soluk and Collins 1988, Sih et al. 1998). A significant $t$-test would indicate an emergent multiple-predator effect (MPE) with either greater than predicted mortality (risk enhancement) or lower than expected mortality (risk reduction). We then utilized actual vs. expected mortality rates to calculate the relative contribution of consumptive vs. nonconsumptive effects in explaining patterns of mud crab mortality. Because we observed risk reduction, we calculated the proportion of the effect that was consumptive (CE) using the following equation:

$$
\mathrm{CE}=M_{(\mathrm{MC}) \mathrm{T}+\mathrm{BC}^{\mathrm{a}}} / M_{(\mathrm{MC}) \mathrm{T}+\mathrm{BC}^{\mathrm{e}}}
$$

where $M_{(\mathrm{MC}) \mathrm{T}+\mathrm{BC}^{\mathrm{a}}}$ is the actual and $M_{(\mathrm{MC}) \mathrm{T}+\mathrm{BC}}$ is the expected mortality from both predators combined. We then used this calculation to quantify the relative importance of nonconsumptive effects (NCE) in our system:

$$
\mathrm{NCE}=1-\mathrm{CE} .
$$

Increased survival from NCE's could be a consequence of predators interfering with each other or reflect indirect benefits from prey avoidance of predators.

Following the ANOVA on oyster mortality, we compared the actual oyster mortality rate from the blue $\mathrm{crab}+$ mud crab treatment to a predicted value using a multiplicative model for each reef type in both the presence and absence of toadfish. The relative strength of cascading consumptive vs. nonconsumptive effects was calculated using actual vs. predicted mortality with the following two modifications to the above protocol. First, expected mortality rates from blue crabs and mud crabs together were corrected to account for mud crabs that were consumed by blue crabs in the blue crab + mud crab treatment and by both toadfish and blue crabs in the three predator treatment. In particular, expected oyster mortality was reduced by the average number of oysters consumed/mud crab multiplied by half the number of mud crabs consumed by blue crabs in the blue crab + mud crab treatment. We multiplied the number of oysters consumed per crab by half of the number of mud crabs consumed because these crabs likely consumed oysters prior to being eaten, and we assumed that mud crab mortality was linear throughout each trial. Second, consumptive effects for the three predator treatment were calculated by dividing the actual mortality rate from the three-predator treatment (1) by the expected value for all three predators together 

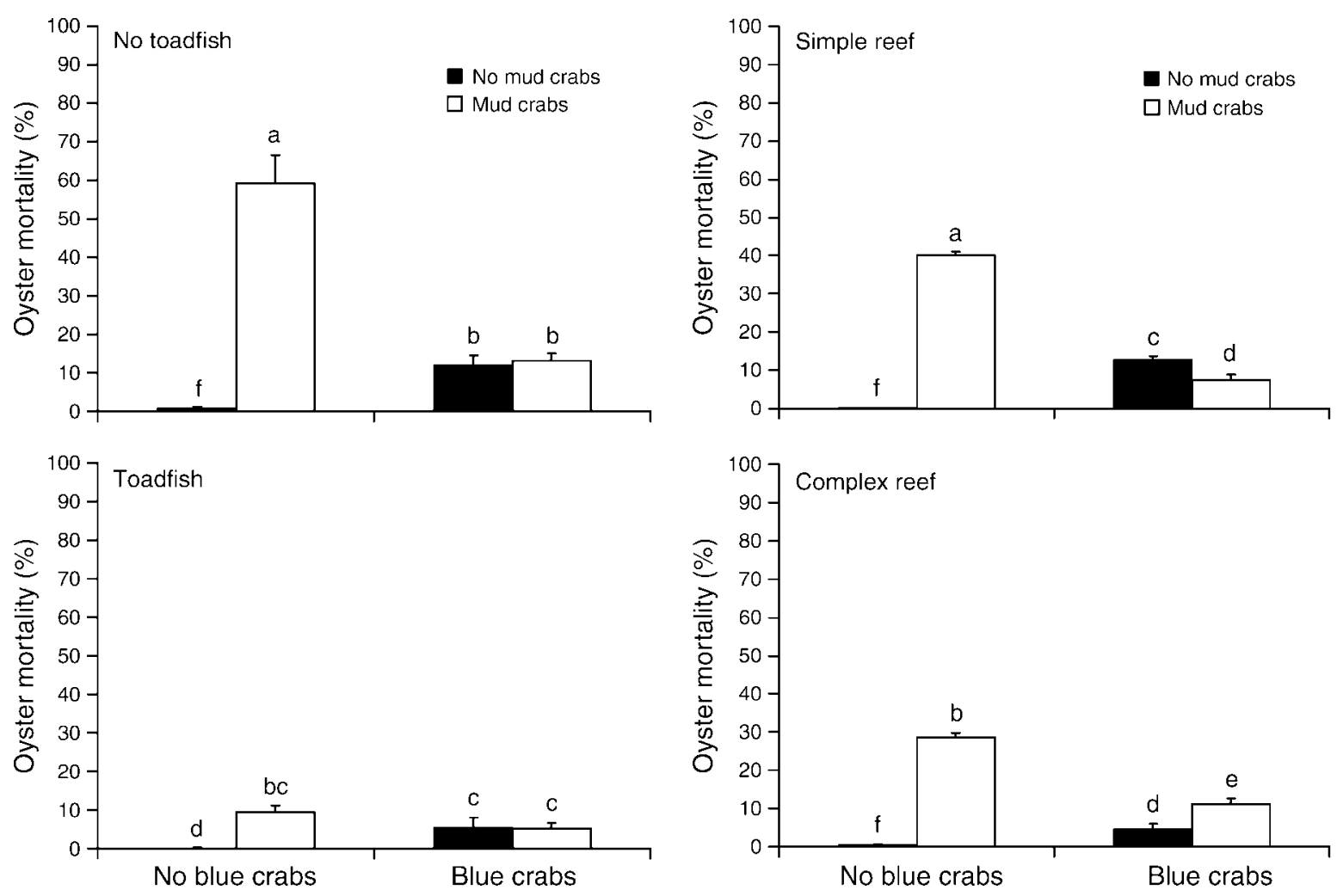

FIG. 2. The effects of toadfish, blue crab, and mud crab presence on oyster mortality. SNK (Student-Newman-Keuls) post hoc results are represented with letters above each error bar (bars with different letters above them are significantly different at $P<0.05)$. Error bars indicate $+\mathrm{SE}$.

(using a multiplicative risk model) to determine if toadfish influence the two crab predators above and beyond its impacts on either individually, and (2) by the expected value for the blue crab + mud crab treatment to determine the strength of the total interference interaction among the three predators. The nonconsumptive effect was partitioned between both crabs together vs. toadfish predators by dividing the actual oyster mortality from the blue crab + mud crab treatment by the oyster mortality from the three predator treatment in each structure level to determine the proportion of the NCE that is mediated by crab interference interactions.

\section{RESULTS}

Habitat complexity and predator richness independently affected cascading interactions among toadfish, blue crabs, mud crabs, and oysters. Juvenile oyster mortality varied with the presence of toadfish, blue crabs, and mud crabs (toadfish $\times$ blue crab $\times$ mud crab interaction, $\left.F_{1,48}=19.9, P<0.0001\right)$. Individually, blue crabs and mud crabs both increased oyster mortality compared to the no predator treatment. But collectively, the interaction between mud crabs and blue crabs resulted in much less oyster mortality compared to that with mud crabs only, because blue crabs also consumed

FIG. 3. The effects of reef habitat complexity, blue crab presence, and mud crab presence on oyster mortality. SNK post hoc results are represented with letters above each error bar (bars with different letters above them are significantly different at $P<0.05)$. Error bars indicate $+\mathrm{SE}$.

mud crabs. The magnitude of crab effects on oysters was also strongly influenced by the presence of toadfish (SNK tests, $P<0.05$; Fig. 2). Toadfish decreased oyster mortality by $83.9 \%$ in enclosures with mud crabs and $54.0 \%$ in enclosures with blue crabs compared to when toadfish were absent. In enclosures with all three predators, toadfish reduced oyster mortality from the two crab predators collectively by $60.4 \%$. Although oyster mortality from enclosures with mud crabs was much greater than from those with both crab species together in the absence of toadfish, it did not differ in the presence of toadfish. Oyster mortality from enclosures with blue crabs vs. those with both crab species did not differ in either the presence or absence of toadfish.

Juvenile oyster mortality also varied with habitat structure, blue crab presence, and mud crab presence (habitat $\times$ blue crab $\times$ mud crab interaction, $F_{1,48}=10.9$, $P=0.002)$. Habitat complexity significantly reduced oyster mortality from either crab species when alone (SNK tests, $P<0.05$; Fig. 3). In the absence of blue crabs, mud crabs increased oyster mortality per day by $39.6 \%$ on simple reefs and $29.2 \%$ on complex reefs. Similarly, blue crabs when alone increased oyster mortality per day to $12.8 \%$ on simple reefs and $4.6 \%$ on complex reefs. However, habitat complexity in- 
TABLE 1. The actual vs. expected effects of mud crabs and blue crabs on percentage oyster mortality in high- vs. low-complexity reefs and in the presence vs. absence of toadfish.

\begin{tabular}{|c|c|c|c|c|c|c|c|}
\hline \multirow[b]{3}{*}{ Toadfish } & \multirow{3}{*}{$\begin{array}{c}\text { Reef } \\
\text { structure } \\
\text { level }\end{array}$} & \multicolumn{4}{|c|}{ Predator treatment } & \multirow[b]{3}{*}{$P$} & \multirow{3}{*}{$\begin{array}{c}\text { Consumptive } \\
\text { effect }\end{array}$} \\
\hline & & \multirow{2}{*}{$\begin{array}{l}\text { Mud } \\
\text { crab }\end{array}$} & \multirow{2}{*}{$\begin{array}{l}\text { Blue } \\
\text { crab }\end{array}$} & \multicolumn{2}{|c|}{ Mud crab $\times$ blue crab } & & \\
\hline & & & & Expected & Actual & & \\
\hline & Low & $39.1 \%(0.9 \%)$ & $12.8 \%(1.0 \%)$ & $46.9 \%(11.7 \%)$ & $7.4 \%(2.3 \%)$ & $0.02 *$ & $15.8 \%$ \\
\hline & High & $28.3 \%(1.0 \%)$ & $4.6 \%(1.6 \%)$ & $31.6 \%(8.2 \%)$ & $11.0 \%(1.9 \%)$ & $0.05 *$ & $34.8 \%$ \\
\hline No toadfish & & $59.2 \%(7.4 \%)$ & $11.9 \%(2.6 \%)$ & $64.0 \%(7.0 \%)$ & $13.2 \%(1.8 \%)$ & 0.003* & $20.6 \%$ \\
\hline Toadfish & & $9.2 \%(1.7 \%)$ & $5.5 \%(2.6 \%)$ & $14.1 \%(1.9 \%)$ & $5.2 \%(1.4 \%)$ & $0.006^{*}$ & $36.8 \%$ \\
\hline
\end{tabular}

Notes: Values in parenthesis indicate + SE. $P$ values are provided for unpaired $t$ tests comparing actual vs. expected values with both crab predators together and are marked with an asterisk where significant at $P<0.05$. Expected mortality was calculated using a multiplicative risk model, where $M$ is mortality: mud crab $M+$ blue crab $M-$ (blue crab $M \times$ blue crab $M$ ). The relative strength of the consumptive effect was calculated by dividing the actual effect by the expected effect, and the remainder was ascribed to the nonconsumptive effect (NCE).

$\dagger$ For the treatments with toadfish, the total nonconsumptive effect indicates the collective strength of all interference interactions among the three predators: 1 - (actual three-predator treatment $M$ /expected mud crab $\times$ blue crab $M$ ). This NCE was partitioned between crabs (pooled) and toadfish: the relative crab effect was calculated by dividing the actual oyster mortality in the presence of all three predators by the oyster mortality from both crabs together, and the remainder was ascribed to the toadfish effect.

creased oyster mortality when exposed to both crab predators. Oyster mortality was significantly higher on simple reefs in the presence of either predator alone than from the two predators together. But oyster mortality from both predators together was intermediate between that of each crab predator alone on complex reefs.

Predator interactions tended to reduce crab consumption of juvenile oysters, though the strength of the reduction depended on the level of habitat complexity and toadfish presence (Table 1). In simple reefs, interference interactions between mud crabs and blue crabs decreased predation rates by $84.5 \%$ compared to expected values. Blue crabs consumed $91.3 \%$ of the available oysters when alone on simple reefs and in the absence of toadfish, so this reduction in oyster mortality is likely an underestimate. For example, if additional oyster prey would have increased consumption rates of blue crabs, expected predation by both predators are underestimated for simple reefs. Reef complexity reduced the strength of crab interference interactions by $19.0 \%$. On more complex reefs, the two crabs together consumed $91.9 \%$ of available oyster prey in the absence of toadfish. Thus, it is likely that prey depletion also resulted in underestimation of the strength of nonconsumptive effects in this study. Toadfish reduced mud crab and blue crab consumption of oysters in both simple and complex habitats; these reductions in collective crab predation rates were consistent with expected reductions from the effects of each crab species individually. Partitioning the relative strength of toadfish vs. combined crab interference interactions determined that toadfish accounted for approximately twothirds of the strength of nonconsumptive effects.

Toadfish and blue crabs interacted to affect mud crab mortality (toadfish $\times$ blue crab interaction: $F_{1,24}=8.2$, $P=0.009$; Fig. 4), and these effects were consistent across simple and complex reefs (habitat complexity $\times$ toadfish $\times$ blue crab interaction: $F_{1,24}=0.8, P=0.38$ ). In the absence of toadfish, blue crabs increased mud crab mortality sixfold (SNK test: $P<0.05$ ). In contrast, blue crabs in the presence of toadfish did not increase mud crab mortality. This interference interaction reduced mud crab mortality by approximately two-thirds (Table 2). Toadfish alone also did not affect mud crab mortality relative to the no top-predator treatment.

\section{Discussion}

Predicting the effects of habitat complexity on predator-prey dynamics requires a thorough understanding of how variation in habitat complexity influences interactions among predators and the subsequent ability of predators and prey to locate and capture or avoid each other. Here we found that whether habitat complexity strengthens or weakens trophic cascades in oyster reefs is largely dependent upon the predator regime present on the reef. In the absence of toadfish,

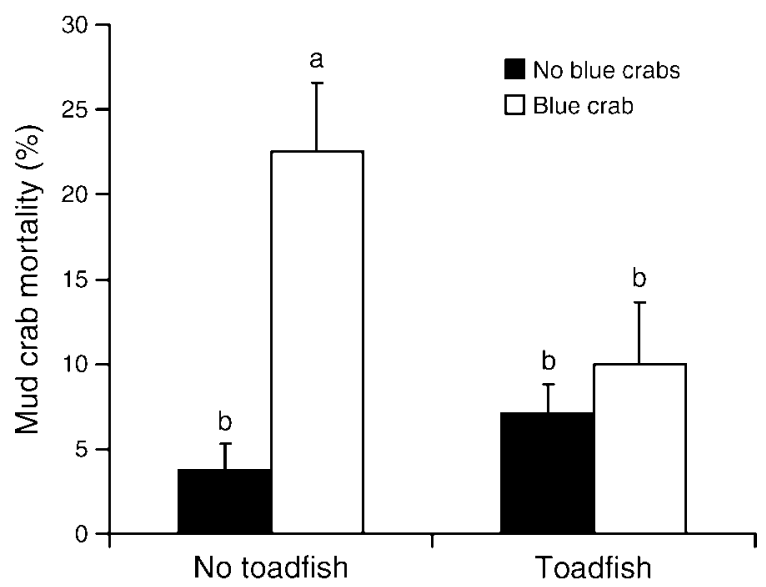

FIG. 4. The effects of toadfish and blue crab presence on mud crab mortality. SNK post hoc results are represented with letters above each error bar (bars with different letters above them are significantly different at $P<0.05$ ). Error bars indicate + SE. 
TABLE 1. Extended.

Nonconsumptive effect

\begin{tabular}{lccc}
\hline Total & Total $\dagger$ & Crab & Toadfish \\
\hline $84.2 \%$ & & & \\
$65.2 \%$ & & & \\
$79.4 \%$ & $92.1 \%$ & $38.8 \%$ & $61.2 \%$ \\
$63.2 \%$ & & & \\
\hline
\end{tabular}

habitat complexity dampened the strength of trophic cascades on oyster reefs when both crab species were together even though blue crab consumption of mud crabs did not differ between simple and complex reefs. Therefore, interference interactions among the two crab species likely resulted in lower than expected oyster mortality rates in the simple reefs, whereas habitat complexity may have reduced the strength of this interference interaction. Furthermore, prey depletion in the combined crab predator treatment on complex reefs suggests that oyster mortality may be underestimated in this treatment.

Our results also suggest that predator identity determines how habitat complexity will influence the strength of trophic cascades. In this and other studies, toadfish elicited strong nonconsumptive effects on mud crabs even in complex habitats where they were no longer capable of capturing mud crabs and where toadfish chemical cues were likely diffused (Grabowski 2004, Grabowski and Kimbro 2005). In contrast, our results suggest that habitat complexity in the absence of toadfish released mud crabs to forage more effectively on oysters by reducing interference from blue crabs: although we did not quantify relative oyster consumption of each crab species when together, oyster mortality rates from combined crab predation on more complex reefs were almost double those from blue crab consumption of oysters alone. Thus toadfish, rather than blue crabs, induce stronger mud crab avoidance behaviors (Table 1). Our study also illustrates that ecologists will benefit from considering how prey respond to different predators to reveal how habitat complexity influences predator-prey interactions more generally.

The experiment was conducted in mesocosms located within one flow-through settling tank. Therefore, chemical cues from predators in some mesocosms could have confounded experimental trials in nearby predatorfree mesocosms. Behavioral effects of top predators on mud crabs may have been underestimated if predator cues spilled over into control mesocosms and induced mud crabs on these reefs to forage less frequently. However, spillover cues (if any) did not prevent mud crabs from consuming more oysters in mesocosms without top predators.

The presence of multiple top predators increased the magnitude of the trophic cascade in oyster reefs. Interestingly, this effect occurred despite the fact that toadfish greatly reduced blue crab foraging rates on mud crabs (i.e., toadfish increased oyster survivorship while also increasing mud crab survivorship). Toadfish and blue crabs did not consume one another, but toadfish may have interfered with blue crabs by inducing them to chase or avoid toadfish. In addition, toadfish may have inhibited blue crab consumption of mud crabs by modifying mud crab behavior since toadfish induce mud crabs to seek refuge deeper within the shell matrix and to move less frequently (Grabowski 2004, Grabowski and Kimbro 2005). This anti-predator behavior may reduce their risk of being consumed by other predators such as blue crabs that forage at the surface of the reef by decreasing blue crab-mud crab encounter rates and/or blue crab capture rates. Although modifications in shared prey behavior can result in emergent MPEs, empirical demonstrations of predator-induced modifications in prey behavior facilitating other predators are far more common than altered prey behavior resulting in reduced prey risk (Soluk and Collins 1988, Martin et al. 1989, Sih et al. 1998, Eklov and VanKooten 2001, Finke and Denno 2002).

Emergent effects of predator-predator interactions presumably have direct and indirect consequences for multiple trophic levels. Yet empiricists rarely examine multiple-predator effects across more than two trophic levels. In our study, interactions among these two top and one intermediate (mud crab) predators influenced the strength of cascading effects for basal prey, the

TABLE 2. The actual vs. expected effects of toadfish and blue crabs on mud crab mortality.

\begin{tabular}{|c|c|c|c|c|c|}
\hline \multirow{2}{*}{$\begin{array}{l}\text { Predator } \\
\text { treatment }\end{array}$} & \multicolumn{2}{|c|}{ Mud crab mortality } & \multirow[b]{2}{*}{$P$} & \multirow{2}{*}{$\begin{array}{c}\text { Consumptive } \\
\text { effect }\end{array}$} & \multirow{2}{*}{$\begin{array}{c}\text { Nonconsumptive } \\
\text { effect }\end{array}$} \\
\hline & Expected & Actual & & & \\
\hline Blue crab & & $22.5 \%(4.1 \%)$ & & & \\
\hline Toadfish & & $7.1 \%(1.7 \%)$ & & & \\
\hline Blue crab $\times$ toadfish & $28.3 \%(3.2 \%)$ & $10.0 \%(3.6 \%)$ & $0.008^{*}$ & $35.3 \%$ & $64.7 \%$ \\
\hline
\end{tabular}

Notes: Values in parenthesis indicate one standard error. The $P$ value is provided for the unpaired $t$ test comparing actual vs. expected values and was marked with an asterisk because the test was significant at $P<0.05$. Expected mortality was calculated using a multiplicative risk model: blue crab $M+$ toadfish $M$ - (blue crab $M \times$ toadfish $M$ ). The relative strength of the consumptive effect was calculated by dividing the actual effect by the expected effect, and the remainder was ascribed to the nonconsumptive effect. 

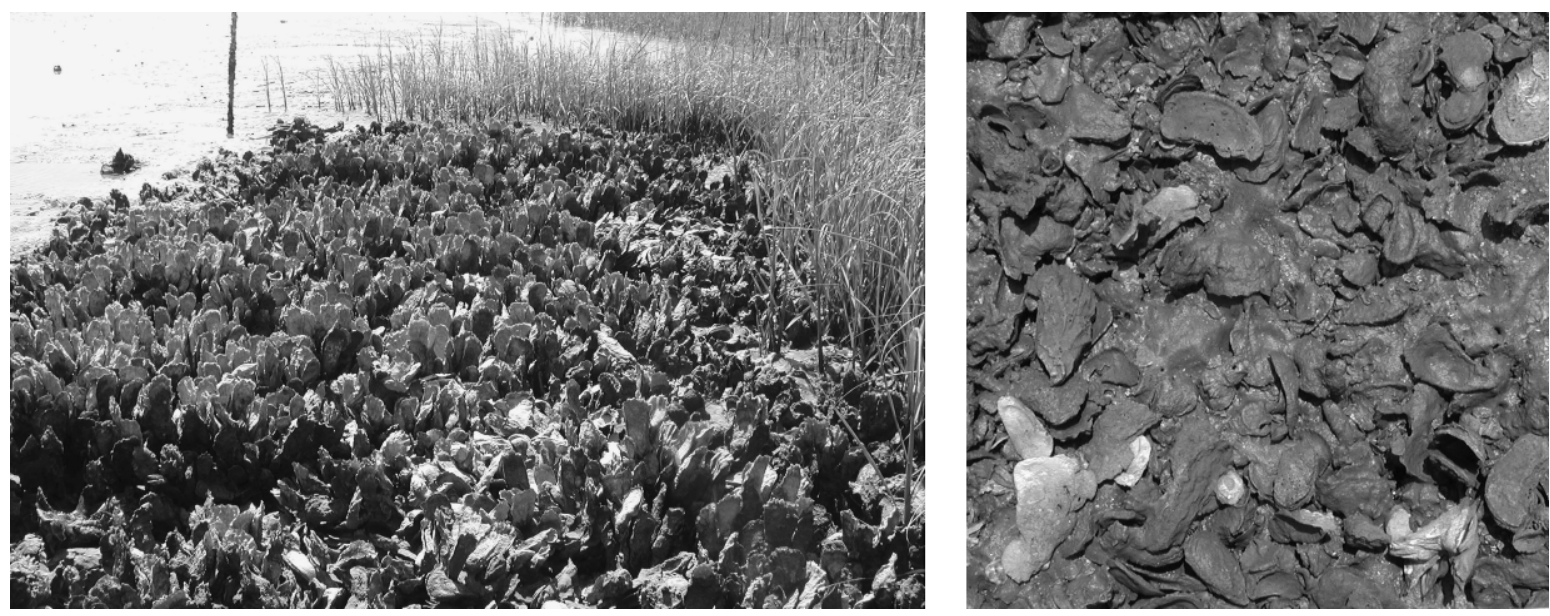

Plate 1. Oyster reefs constructed in this mesocosm study mimicked those in the wild in coastal North Carolina (USA). Our complex reefs (left) were similar to intact reefs with vertically upright, living oysters, which create refuge for mud crabs and other intermediate predators in this system. Our simple reefs (right), were constructed to replicate reefs that are highly degraded, contain few living oysters on them, and have little to no vertical relief. Photo credit: J. H. Grabowski.

juvenile oyster. Interference interactions among the three species resulted in a $\sim 80-90 \%$ reduction in oyster mortality rates (Table 1). This reduction in oyster mortality was a consequence of (1) interference interactions among the two crab species, which resulted in up to an $\sim 80 \%$ reduction in oyster mortality independent of toadfish effects, and (2) toadfish suppression of oyster consumption rates for each crab species, which amounted to as much as a $\sim 95 \%$ reduction in oyster mortality. Mud crab mortality rates were largely reduced when both top predators were together, so that classical, density-mediated cascades can not explain reduced oyster mortality in this system. Therefore, behavioral effects largely mediate interactions among predators and maintain the strength of resultant cascading effects in this system. Although our additive design did not permit examination of the relative strength of intraspecific vs. interspecific interference interactions for each top predator, a substitutive design likely would have produced similar effects since blue crabs aggressively interfere with most predators, especially other blue crabs (Clark et al. 1999, O’Connor et al. 2008).

Because we conducted a mesocosm experiment with a simplified food web, we may have inadvertently overestimated the importance of these particular species interactions and trophic cascades. For example, our study design may have reduced omnivory in this system, which can attenuate cascading effects of top predators (Strong 1992, Polis and Strong 1996, McCann et al. 1998). Yet we argue that our experimental system may be indicative of interactions in natural settings for the following reasons. First, we simulated a realistic oyster community by including several important oyster reef species across multiple trophic levels (Virnstein 1977, Martin et al. 1989, Hines et al. 1990, Micheli 1997, Grabowski 2004). And second, many of our results are consistent with corresponding field manipulations in this system (Nakaoka 2000, Grabowski et al. 2005, O'Connor et al. 2008). For instance, Nakaoka (2000) found greater bivalve mortality rates in oyster reefs than in adjacent mud bottom, suggesting that habitat complexity provided by oyster reefs reduces interference interactions among predators such as occurred between mud crabs and blue crabs on complex reefs in this study. Further investigation of these processes is merited in the field to continue examining how habitat complexity influences trophic cascades.

Empiricists have demonstrated separately that trophic cascades and emergent multiple-predator effects, two current focal points of the field of community ecology, are both influenced by a key component of the physical world, habitat complexity. Therefore, examination of how habitat complexity influences the cascading effects of multiple predators will augment traditional attempts to conceptualize the mechanisms that structure ecological communities. In oyster reef communities, habitat complexity reduced both crabs' consumption of oysters when alone, but enhanced combined blue crab and mud crab predation on oysters. Thus habitat complexity likely reduces the strength of interference interactions among predators that actively pursue their prey. In contrast, toadfish reduced not only blue crab consumption of mud crabs and oysters but also mud crab predation on oysters, and these effects were independent of variation of habitat complexity. Toadfish indirectly benefited both its own prey (mud crabs) and juvenile oysters even in complex habitats largely because toadfish strongly influence mud crab behavior, and this effect cascades both up and down the food chain. Collectively our results suggest that predator identity and habitat complexity both mediate trophic cascades because they influence the strength of behavioral interactions. Activ- 
ities that further degrade habitats and reduce elements that create complexity such as living, vertically upright oysters will influence community structure not only by destroying refuge availability for prey but also through more subtle modifications in predator-predator interactions and predator-prey dynamics that are often mediated by behavioral mechanisms.

\section{ACKNOWLEDGMENTS}

E. Calvert, M. Dolan, and R. Wagaman helped in the field and the lab. This manuscript was greatly enhanced by many substantive comments from two anonymous reviewers. This project was supported by funding from the NOAA-National Estuarine Research Fellowship Program (NOAA award no. 97-040-NOC) and the North Carolina Fishery Resource Grant Program (FRG Project no. 97-EP-06). This work was also supported by the facilities and staff of UNC-IMS.

\section{Literature Cited}

Abrams, P. A. 1982. Functional responses of optimal foragers. American Naturalist 120:382-390.

Bell, S. S., E. D. McCoy, and H. R. Mushinsky, editors. 1991. Habitat structure: the physical arrangement of objects in space. Chapman and Hall, New York, New York, USA.

Bruno, J. F., and M. I. O'Conner. 2005. Cascading effects of predator diversity and omnivory in a marine food web. Ecology Letters 8:1048-1056.

Byrnes, J. E., J. J. Stachowicz, K. Hultgren, A. R. Hughes, S. V. Olyarnik, and C. S. Thornber. 2006. Predator diversity strengthens trophic cascades in kelp forests by modifying herbivore behavior. Ecology Letters 9:61-71.

Carpenter, S. R., J. F. Kitchell, and J. R. Hodgson. 1985. Cascading trophic interactions and lake productivity. BioScience 35:634-639.

Clark, M. E., T. G. Wolcott, D. L. Wolcott, and A. H. Hines. 1999. Intraspecific interference among foraging blue crabs Callinectes sapidus: interactive effects of predator density and prey patch distribution. Marine Ecology Progress Series 178: 69-78.

Coen, L. D., M. W. Luckenbach, and D. L. Breitburg. 1999. The role of oyster reefs as essential fish habitat: a review of current knowledge and some new perspectives. American Fisheries Society Symposium 22:438-454.

Coleman, F. C., and S. L. Williams. 2002. Overexploiting marine ecosystem engineers: potential consequences for biodiversity. Trends in Ecology and Evolution 17:40-44.

Crowder, L. B., and W. E. Cooper. 1982. Habitat structural complexity and the interaction between bluegills and their prey. Ecology 63:1802-1813.

Crowder, L. B., D. D. Squires, and J. A. Rice. 1997. Nonadditive effects of terrestrial and aquatic predators on juvenile estuarine fish. Ecology 78:1796-1804.

Day, R. W., and G. P. Quinn. 1989. Comparisons of treatments after an analysis of variance in ecology. Ecological Monographs 59:433-463.

Diehl, S. 1988. Foraging efficiency of three freshwater fish: effects of structural complexity and light. Oikos 53:207-214.

Diehl, S. 1992. Fish predation and benthic community structure: the role of omnivory and habitat complexity. Ecology 73:1646-1661.

Duffy, J. E. 2002. Biodiversity and ecosystem function: the consumer connection. Oikos 99:201-219.

Eklov, P., and T. VanKooten. 2001. Facilitation among piscivorous predators: effects of prey habitat use. Ecology 82:2486-2494.

Finke, D. L., and R. F. Denno. 2002. Intraguild predation diminished in complex-structured vegetation: implications for prey suppression. Ecology 83:643-652.
Grabowski, J. H. 2004. Habitat complexity disrupts predatorprey interactions but not the trophic cascade on oyster reefs. Ecology 85:995-1004.

Grabowski, J. H., A. R. Hughes, D. L. Kimbro, and M. A. Dolan. 2005. How habitat setting influences restored oyster reef communities. Ecology 86:1926-1935.

Grabowski, J. H., and D. L. Kimbro. 2005. Predator-avoidance behavior extends trophic cascades to refuge habitats. Ecology 86:1312-1319.

Grabowski, J. H., and S. P. Powers. 2004. Habitat complexity mitigates trophic transfer on oyster reefs. Marine Ecology Progress Series 277:291-295.

Griffen, B. D., and J. E. Byers. 2006. Partitioning mechanisms of predator interference in different habitats. Oecologia 146: 608-614.

Heck, K. L., Jr., and T. A. Thoman. 1981. Experiments on predator-prey interactions in vegetated aquatic habitats. Journal of Experimental Marine Biology and Ecology 53: $125-134$.

Hines, A. H., A. M. Haddon, and L. A. Wiechert. 1990. Guild structure and foraging impact of blue crabs and epibenthic fish in a subestuary of Chesapeake Bay. Marine Ecology Progress Series 67:105-126.

Holbrook, S. J., and R. J. Schmitt. 1988. The combined effects of predation risk and food reward on patch selection. Ecology 69:125-134.

Huffaker, C. B. 1958. Experimental studies on predation: dispersion factors and predator-prey oscillations. Hilgardia 27:343-383.

Hughes, A. R., and J. H. Grabowski. 2006. Habitat context influences predator interference interactions and the strength of resource partitioning. Oecologia 149:256-264.

Jackson, J. B. C., et al. 2001. Historical overfishing and the recent collapse of coastal ecosystems. Science 293:629-638.

Lenihan, H. S. 1999. Physical-biological coupling on oyster reefs: how habitat structure influences individual performance. Ecological Monographs 69:251-275.

Lenihan, H. S., C. H. Peterson, J. E. Byers, J. H. Grabowski, G. W. Thayer, and D. R. Colby. 2001. Cascading of habitat degradation: Oyster reefs invaded by refugee fishes escaping stress. Ecological Applications 11:764-782.

Lima, S. L., and L. M. Dill. 1990. Behavioral decisions made under the risk of predation: a review and prospectus. Canadian Journal of Zoology 68:619-640.

Martin, T. H., R. A. Wright, and L. B. Crowder. 1989. Nonadditive impact of blue crabs and spot on their prey assemblages. Ecology 70:1935-1942.

McCann, K. S., A. Hastings, and D. R. Strong. 1998. Trophic cascades and trophic trickles in pelagic food webs. Proceedings of the Royal Society B 265:205-209.

McDermott, J. J., and F. B. Flower. 1952. Preliminary studies of the common mud crabs on oyster beds of Delaware Bay. National Shellfisheries Association Convention Address 1952:47-50.

Meyer, D. L., E. C. Townsend, and P. L. Murphy. 1996. Final report for the project the evaluation of restored wetlands and enhancement methods for existing restorations. NOAA, Silver Spring, Maryland, USA.

Micheli, F. 1997. Effects of predator foraging behavior on patterns of prey mortality in marine soft bottoms. Ecological Monographs 67:203-224.

Morin, P. J. 1995. Functional redundancy, non-additive interactions, and supply-side dynamics in experimental pond communities. Ecology 76:133-149.

Murdoch, W. W., and A. Oaten. 1975. Predation and population stability. Advances in Ecological Research 9: $1-131$.

Nakaoka, M. 2000. Nonlethal effects of predators on prey populations: predator-mediated change in bivalve growth. Ecology 81:1031-1045. 
O'Connor, N. E., J. H. Grabowski, L. M. Ladwig, and J. F. Bruno. 2008. Simulated predator extinctions: predator identity affects survival and recruitment of oysters. Ecology 89:428-438.

Paine, R. T. 1966. Food web complexity and species diversity. American Naturalist 100:65-75.

Peterson, C. H., J. H. Grabowski, and S. P. Powers. 2003. Estimated enhancement of fish production resulting from restoring oyster reef habitat: quantitative valuation. Marine Ecology Progress Series 264:249-264.

Polis, G. A., and D. R. Strong. 1996. Food web complexity and community dynamics. American Naturalist 147:813-846.

Rothschild, B. J., J. S. Ault, P. Goulletquer, and M. Heral. 1994. Decline of the Chesapeake Bay oyster population: a century of habitat destruction and overfishing. Marine Ecology Progress Series 111:29-39.

Schmitz, O. J., P. A. Hamback, and A. P. Beckerman. 2000. Trophic cascades in terrestrial systems: a review of the effects of carnivore removals on plants. American Naturalist 155: $141-153$.

Schmitz, O. J., V. Krivan, and O. Ovadia. 2004. Trophic cascades: the primacy of trait-mediated indirect interactions. Ecology Letters 7:153-163.

Schmitz, O. J., and L. Sokol-Hessner. 2002. Linearity in the aggregate effects of multiple predators in a food web. Ecology Letters 5:168-172.

Shurin, J. B., E. T. Borer, E. W. Seabloom, K. Anderson, C. A. Blanchette, B. Broitman, S. D. Cooper, and B. S. Halpern. 2002. A cross-ecosystem comparison of the strength of trophic cascades. Ecology Letters 5:785-791.

Siddon, C. E., and J. D. Witman. 2004. Behavioral indirect interactions: multiple predator effects and prey switching in the rocky subtidal. Ecology 85:2938-2945.

Sih, A., P. Crowley, M. McPeek, J. Petranka, and K. Strohmeier. 1985. Predation, competition, and prey communities: a review of field experiments. Annual Review of Ecology and Systematics 16:269-311.

Sih, A., G. Englund, and D. Wooster. 1998. Emergent impacts of multiple predators on prey. Trends in Ecology and Evolution 13:350-355.
Sih, A., L. B. Kats, and R. D. Moore. 1992. Effects of predatory sunfish on the density, drift, and refuge use of stream salamander larvae. Ecology 73:1418-1430.

Soluk, D. A., and N. C. Collins. 1988. Synergistic interactions between fish and stoneflies: facilitation and interference among stream predators. Oikos 52:94-100.

Strong, D. R. 1992. Are trophic cascades all wet? Differentiation and donor-control in speciose ecosystems. Ecology 73: 747-754.

Swisher, B. J., D. A. Soluk, and D. H. Wahl. 1998. Nonadditive predation in littoral habitats: influences of habitat complexity. Oikos 81:30-37.

Trussell, G. C., P. J. Ewanchuk, and C. M. Matassa. 2006. Habitat effects on the relative importance of trait and density-mediated indirect interactions. Ecology Letters 9: $1245-1252$.

Ulanowicz, R. E., and J. H. Tuttle. 1992. The trophic consequences of oyster stock rehabilitation in Chesapeake Bay. Estuaries 15:298-306.

Underwood, A. J. 1981. Techniques of analysis of variance in experimental marine biology and ecology. Oceanography and Marine Biology Annual Review 19:513-605.

Virnstein, R. W. 1977. The importance of predation by crabs and fishes on benthic infauna in Chesapeake Bay. Ecology 58:1199-1217.

Wells, H. W. 1961. The fauna of oyster beds, with special reference to the salinity factor. Ecological Monographs 31: 239-266.

Werner, E. E., and S. D. Peacor. 2003. A review of traitmediated indirect interactions in ecological communities. Ecology 84:1083-1100.

Wilson, C. A., J. M. Dean, and R. Radtke. 1982. Age, growth rate and feeding habits of the oyster toadfish, Opsanus tau (Linnaeus) in South Carolina. Journal of Experimental Marine Biology and Ecology 62:251-259.

Wissinger, S., and J. McGrady. 1993. Intraguild predation and competition between larval dragonflies: direct and indirect effects on shared prey. Ecology 74:207-218. 